\title{
ANALISIS FAKTOR YANG MEMPENGARUHI KEJADIAN STUNTING PADA BALITA DI WILAYAH PUSKESMAS KABUPATEN PATI
}

\author{
Sri Hadi Sulistiyaningsih ${ }^{1}$, Siti Niamah \\ ${ }^{1}$ Staff Dosen Program Studi Sarjana Kebidanan STIKes Bakti Utama Pati \\ ${ }^{2}$ Staff Dosen Program Studi Diploma Tiga Kebidanan STIKes Bakti Utama Pati \\ Alamat Korespondensi: mahira.hsp@gmail.com
}

\begin{abstract}
Abstrak
Stunting adalah kondisi gagal tumbuh pada anak balita (bayi dibawah lima tahun) akibat dari kekurangan gizi kronis sehingga anak terlalu pendek untuk usianya. Kekurangan gizi terjadi sejak bayi dalam kandungan dan pada masa awal setelah bayi lahir akan tetapi, kondisi stunting baru nampak setelah bayi berusia 2 tahun. Tujuan penelitian ini adalah untuk menganalisis faktor-faktor yang mempengaruhi kejadian stunting pada balita di Wilayah Puskesmas Kabupaten Pati. Penelitian merupakan penelitian explanatory research dengan pendekatan metode cross sectional. Sampel penelitian ini adalah 59 balita yang megalami kejadian stunting yang diambil dengan menggunakan tehnik total sampling. Analisis yang digunakan adalah uji Chi Square dan uji analisis regresi logistik berganda. Hasil penelitian menunjukkan adanya hubungan Pengetahuan ( $\mathrm{p}$ value $=0,039)$, Berat Badan Lahir ( $\mathrm{p}$ value $=0,020)$, Faktor Ekonomi ( $\mathrm{p}$ value $=0,001$ ), dan Pola Asuh ( $\mathrm{p}$ value =0,021), Riwayat Pemberian ASI ( $\mathrm{p}$ value $=0,040$ ) dan riwayat penyakit infeksi ( $\mathrm{p}$ value $=0,014$ ) dengan kejadian stunting. Variabel yang berpengaruh secara bersama - sama dengan kejadian stunting adalah Berat Badan Lahir ( $p$ value $=0,007)$, Faktor Ekonomi $(\mathrm{p}$ value $=0,011)$, dan Pola Asuh ( $\mathrm{p}$ value $=0,004$ ). Berdasarkan hasil penelitian disarankan agar masyarakat terutama ibu dan keluarga yang memiliki anak dibawah 5 tahun agar mematuhi dan melaksanakan program terkait dengan pemberian gizi seimbang pada balita dan menambah kreatifitas untuk pemberian makanan pada anaknya.
\end{abstract}

Kata kunci : Faktor Penyebab Stunting, Balita

\begin{abstract}
Stunting is a condition of failure to thrive in children under five years of age as a result of chronic malnutrition so that the child is too short for his age. Malnutrition occurs since the baby is in the womb and the early days after the baby is born, however, the condition of stunting only appears after the baby is 2 years old. The purpose of this study was to analyze the factors that influence the incidence of stunting in children under five in the Pati District Health Center. This research is explanatory research with a crosssectional approach. The sample of this study was 59 children under five who experienced stunting, which was taken using the total sampling technique. The analysis used is the Chi-Square test and multiple logistic regression analysis. The results showed a relationship between Knowledge ( $\mathrm{p}$-value $=0.039)$, Birth Weight $(\mathrm{p}$-value $=0.020)$, Economic Factors $(\mathrm{p}$-value $=0.001)$, and Parenting Patterns $(\mathrm{p}$-value $=0.021)$, History of Breastfeeding ( $p$-value $=0.040)$. ) and a history of infectious disease ( $p$-value $=0.014$ ) with the incidence of stunting. The variables that influence stunting together are birth weight ( $p$-value $=0.007$ ), economic factors ( $p$-value $=0.011)$, and parenting style ( $\mathrm{p}$-value $=0.004)$. Based on the results of the study, it is suggested that the community, especially mothers and families with children under 5 years of age, comply with and implement programs related to the provision of balanced nutrition for toddlers and increase creativity in feeding their children.
\end{abstract}

Keywords: Factors that cause stunting, toddlers 


\section{PENDAHULUAN}

Stunting adalah kondisi gagal tumbuh pada anak balita (bayi dibawah lima tahun) akibat dari kekurangan gizi kronis sehingga anak terlalu pendek untuk usianya. Kekurangan gizi terjadi sejak bayi dalam kandungan dan pada masa awal setelah bayi lahir akan tetapi, kondisi stunting baru nampak setelah bayi berusia 2 tahun. Balita pendek (stunted) dan sangat pendek (severely stunted) adalah balita dengan panjang badan $(\mathrm{PB} / \mathrm{U})$ atau tinggi badan (TB/U) menurut umurnya dibandingkan dengan standar baku WHOMGRS (Multicentre Growth Reference Study). Sedangkan definisi stunting menurut Kementerian Kesehatan (Kemenkes) adalah anak balita dengan nilai z-scorenya kurang dari -2SD/standar deviasi (stunted) dan kurang dari - 3SD (severely stunted).(Kemenkes RI ,2018).

Kejadian balita pendek atau biasa disebut dengan stunting merupakan salah satu masalah gizi yang dialami oleh balita di dunia saat ini. Pada tahun 2017, 22,2\% atau sekitar 150,8 juta balita di dunia mengalami stunting. Namun angka ini sudah mengalami penurunan jika dibandingkan dengan angka stunting pada tahun 2000 yaitu $32,6 \%$. Pada tahun 2017, lebih dari setengah balita stunting di dunia berasal dari Asia (55\%), sedangkan lebih dari sepertiganya (39\%) tinggal di Afrika. Data prevalensi balita stunting yang dikumpulkan World Health Organization (WHO), Indonesia termasuk ke dalam negara ketiga dengan prevalensi tertinggi di regional Asia Tenggara/South-East Asia Regional (SEAR). Rata-rata prevalensi balita stunting di Indonesia tahun 2005-2017 adalah 36,4\% (Kemenkes RI, 2018)

Menurut WHO, batasan prevalensi stunting suatu wilayah sebesar $20 \%$. Hasil Riset Kesehatan Dasar tahun 2013 dan 2018 dari seluruh provinsi di Indonesia secara nasional prevalensi stunting menurun dari $37,2 \%$ menjadi
30,8\%. Meskipun sudah menurun, tetapi masih jauh dari batasan WHO. Tahun 2018 ini, 100 kota/Kabupaten di Indonesia manjadi prioritas penanganan stunting. Di Jawa Tengah masih ada 11 Kabupaten dan Kota yang masih tinggi dalam angka penderita stunting sebanyak 28\%.(Riskesdas,2018)

Menurut UNICEF dalam BAPPENAS (2011), pada dasarnya status gizi anak dapat dipengaruhi oleh faktor langsung dan tidak langsung, faktor langsung yang berhubungan dengan stunting yaitu karakteristik anak berupa jenis kelamin laki-laki, berat badan lahir rendah, konsumsi makanan berupa asupan energi rendah dan asupan protein rendah, faktor langsung lainnya yaitu status kesehatan penyakit infeksi ISPA dan diare. Pola pengasuhan, tidak ASI ekslusif, pelayanan kesehatan berupa status imunisasi yang tidak lengkap, dan karakteristik keluarga berupa pekerjaan orang tua, pendidikan orang tua dan status ekonomi keluarga merupakan faktor tidak langsung yang mempengaruhi stunting.

Berdasarkan Penimbangan Serentak Tahun 2018, kasus stunting sejak 2018 hingga 2019 di Kabupaten Pati semakin bertambah dalam setahun terakhir dan menduduki peringkat kedua se-Jawa Tengah. Terdapat 2 Puskesmas yang prevalensi angka stunting masih tinggi yaitu Puskesmas Jakenen 20,83\% dan Puskesmas Gabus II 20,28\%, hal ini menunjukkan bahwa prevelensi stunting masih diatas batasan WHO yaitu $20 \%$. Pemerintah Kabupaten Pati melalui Dinas Kesehatan (Dinkes) melibatkan dokter spesialis anak dan dokter spesialis gizi klinik mengintervensi untuk menurunkan prevalensi kasus stunting di Wilayah puskesmas yang mengalami kasus stunting.

Tujuan penelitian ini adalah untuk menganalisis faktor-faktor yang mempengaruhi kejadian stunting pada 
balita di Wilayah Puskesmas Kabupaten Pati. Penelitian merupakan penelitian explanatory research dengan pendekatan metode cross sectional.

\section{METODE PENELITIAN}

Jenis penelitian merupakan penelitian explanatory research yang bersifat observasional dengan pendekatan metode cross sectional. Ruang lingkup penelitian ini termasuk dalam lingkup ilmu kesehatan anak. Variabel independen adalah pengetahuan, berat badan lahir, riwayat penyakit infeksi, riwayat pemberian ASI, pola asuh, faktor ekonomi sedangkan variabel dependen adalah stunting. Adapun populasi dalam penelitian ini adalah balita dengan stunting yang berjunlah 59 anak. Tehnik pengambilan sampel menggunakan total sampling. Instrumen yang digunakan dalam bentuk kuesioner tentang pengetahuan, berat badan lahir, riwayat penyakit infeksi, riwayat pemberian ASI, pola asuh, faktor ekonomi dan stunting. Pengolahan data dilakukan dengan cara editing, coding, scoring dan tabulasi data. Sedangkan analisis data meliputi uji univariate, bivariat dengan Chi Square dan multivariate dengan uji regresi logistis berganda. Penelitian ini telah mendapatkan surat keterangan layak etik dari Komisi Etik Penelitian Universitas 'Aisyiyah Yogyakarta .

\section{HASIL PENELITIAN}

Tabel. 1

Distribusi Frekuensi Pengetahuan Ibu tentang Gizi

\begin{tabular}{ccc}
\hline Pengetahuan & Jumlah & $\mathbf{( \% )}$ \\
\hline Baik & 21 & 35.6 \\
Cukup & 25 & 42.4 \\
Kurang & 13 & 22.0 \\
\hline Jumlah & 59 & 100 \\
\hline
\end{tabular}

Tabel 1 menunjukkan bahwa responden yang mempunyai pengetahuan baik sebanyak 21 orang $(35,6 \%)$, pengetahuan cukup 25 orang $(42,4 \%)$ dan pengetahuan kurang sebanyak 13 orang (22\%).

Tabel.2

Distribusi Frekuensi Pemberian ASI Eksklusif

\begin{tabular}{ccc}
\hline Pemberian ASI Eksklusif & Jumlah & $\mathbf{( \% )}$ \\
\hline ASI Eksklusif & 33 & 55,9 \\
Tidak ASi Eksklusif & 26 & 44,1 \\
\hline Jumlah & 59 & 100 \\
\hline
\end{tabular}

Tabel 2 menunjukkan bahwa balita yang diberikan ASI eksklusif sebanyak 33 orang $(55,9 \%)$, balta yang tidak diberikan asi eksklusif sebanyak 26 orang $(44,1 \%$

Tabel. 3

Distribusi Frekuensi Riwayat Penyakit Infeksi

\begin{tabular}{lll}
\hline Riwayat Penyakit Infeksi & Jumlah & $(\%)$ \\
\hline
\end{tabular}




\begin{tabular}{ccc}
\hline Ada Riwayat & 14 & 23.7 \\
Tidak ada riwayat & 45 & 76.3 \\
\hline Jumlah & 59 & 100 \\
\hline
\end{tabular}

Tabel 4 menunjukkan bahwa balita yang mempunyai riwayat infeksi sebanyak 14 orang $(23,7 \%)$

Tabel. 4

Distribusi Frekuensi Pola Asuh

\begin{tabular}{ccc}
\hline Pola Asuh & Jumlah & $(\boldsymbol{\%})$ \\
\hline Baik & 43 & 72,9 \\
Kurang Baik & 16 & 27.1 \\
\hline Jumlah & 59 & 100 \\
\hline
\end{tabular}

Tabel.4 menunjukkan bahwa pola asuh yang diberikan dalam kategori baik sebanyak 43 ornag

dan yang tidak memepunyai riwayat infeksi sebanyak 45 orang $(76,3 \%)$.
$(72,9 \%)$ dan pola asuh kurang baik sebanyak 16 orang $(27,1 \%)$.

Distribusi Frekuensi Berat Badan Lahir

\begin{tabular}{ccc}
\hline Pola Asuh & Jumlah & $(\boldsymbol{\%})$ \\
\hline$\geq 2500$ gram & 43 & 72,9 \\
$<2500$ gram & 16 & 27.1 \\
\hline Jumlah & 59 & 100 \\
\hline
\end{tabular}

Tabel.5 menunjukkan bahwa berat badan lahir bayi $\geq 2500$ gram sebanyak 43 balita $(72,9 \%)$ dan

Distribusi Frekuensi Ekonomi

$$
\text { Tabel.6 }
$$

berat badan lahir <2500 gram sebanyak 16 balita $(27,1 \%)$.

\begin{tabular}{ccc}
\hline Pola Asuh & Jumlah & $(\boldsymbol{\%})$ \\
\hline$\geq$ UMR & 31 & 52,5 \\
< UMR & 28 & 47,5 \\
\hline Jumlah & 59 & 100
\end{tabular}

Berdasarkan tabel 4.6 menunjukkan bahwa ekonomi $\geq$ UMR sebanyak 31 orang $(52,5 \%)$

Tabel .7

Distribusi Frekuensi Kejadian Stunting

\begin{tabular}{ccc}
\hline Pola Asuh & Jumlah & $(\boldsymbol{\%})$ \\
\hline Pendek & 41 & 69,5 \\
Sangat Pendek & 18 & 30,5 \\
\hline Jumlah & 59 & 100 \\
\hline
\end{tabular}

Tabel.7 menunjukkan bahwa balita yang mengalami stunting dan tingkat ekonomi < UMR sebanyak 28 orang $(46,5 \%)$. 
stunting dengan kategori sangat pendek sebanyak 18 orang $(30,5 \%)$.

Tabel.8

Tabulasi Silang Antara Hubungan Pengetahuan Dengan kejadian stunting

\begin{tabular}{|c|c|c|c|c|c|c|c|}
\hline \multirow{3}{*}{ Pengetahuan } & \multicolumn{4}{|c|}{ Stunting } & & & \multirow{3}{*}{$P$ value } \\
\hline & \multicolumn{2}{|c|}{ Pendek } & \multicolumn{2}{|c|}{ Sangat pendek } & \multicolumn{2}{|c|}{ Total } & \\
\hline & $f$ & $\%$ & $\mathrm{f}$ & $\%$ & $\mathrm{f}$ & $\%$ & \\
\hline Baik & 15 & 25,4 & 6 & 10,2 & 21 & 35,6 & 0,039 \\
\hline Cukup & 17 & 28,8 & 8 & 13,6 & 25 & 42,4 & \\
\hline Kurang & 9 & 15,3 & 4 & 6,7 & 13 & 22 & \\
\hline Jumlah & 41 & 69,5 & 18 & 30,5 & 59 & 100 & \\
\hline
\end{tabular}

Berdasarkan hasil uji Chi Square $\mathrm{P}_{\text {value }} 0,039<0,05$, sehingga Ha diterima dan Ho di tolak, yang berarti ada hubungan pengetahuan

Tabel.9

Tabulasi Silang Antara Pemberian ASI Eksklusif dengan Kejadian Stunting di Wilayah Puskemas Kabupaten Pati

\begin{tabular}{lccccccc}
\hline \multirow{2}{*}{$\begin{array}{c}\text { Pemberian ASI } \\
\text { Ekslkusif }\end{array}$} & \multicolumn{9}{c}{ Kejadian Stunting } & \multirow{2}{*}{ Pendek } & \multicolumn{2}{c}{ Sangat Pendek } & \multicolumn{2}{c}{ Total } & \\
\cline { 2 - 7 } & $\mathrm{f}$ & $\%$ & $\mathrm{f}$ & $\%$ & $\mathrm{f}$ & $\%$ & \\
\hline Diberikan & 18 & 30,5 & 8 & 13,6 & 26 & 44,1 & \\
\hline Tidak Diberikan & 23 & 39,0 & 10 & 16,9 & 33 & 55,9 & \multirow{2}{*}{0,040} \\
\hline Jumlah & 41 & 69,5 & 18 & 30,5 & 59 & 100 & \\
\hline
\end{tabular}

Berdasarkan hasil uji Chi Pemberian ASi Eksklusif dengan Square diperoleh $\mathrm{P}_{\text {value }} 0,040<0,05$, sehingga $\mathrm{Ha}$ diterima dan $\mathrm{Ho}$ di tolak, yang berarti ada hubungan

Kejadian Stunting di Wilayah Puskesmas Kabupaten Pati.

Tabel.10

Tabulasi Silang Antara Riwayat Penyakit Infeksi dengan Kejadian Stunting di Wilayah Puskemas Kabupaten Pati

\begin{tabular}{|c|c|c|c|c|c|c|c|}
\hline \multirow{3}{*}{$\begin{array}{c}\text { Riwayat Penyakit } \\
\text { Infeksi }\end{array}$} & \multicolumn{4}{|c|}{ Kejadian Stunting } & & & \multirow{3}{*}{$P$ value } \\
\hline & \multicolumn{2}{|c|}{ Pendek } & \multicolumn{2}{|c|}{ Sangat Pendek } & \multicolumn{2}{|c|}{ Total } & \\
\hline & $\mathrm{f}$ & $\%$ & $\mathrm{f}$ & $\%$ & $\mathrm{f}$ & $\%$ & \\
\hline Tidak Ada Riwayat & 31 & 52,5 & 14 & 23,7 & 45 & 76,3 & \\
\hline Ada Riwayat & 10 & 16,9 & 4 & 6,8 & 14 & 23,7 & 0,014 \\
\hline Jumlah & 41 & 69,5 & 18 & 30,5 & 59 & 100 & \\
\hline
\end{tabular}


Berdasarkan hasil uji $C h i$ Square diperoleh $\mathrm{P}_{\text {value }} 0,014<0,05$, sehingga $\mathrm{Ha}$ diterima dan Ho di tolak, yang berarti ada hubungan
Riwayat Penyakit Infeksi dengan Kejadian Stunting di Wilayah Puskesmas Kabupaten Pati.

Tabel.11

Tabulasi Silang Antara Pola Asuh dengan Kejadian Stunting di Wilayah Puskemas Kabupaten Pati

\begin{tabular}{lccccccc}
\hline \multirow{3}{*}{ Pola Asuh } & \multicolumn{9}{c}{ Kejadian Stunting } & \multirow{2}{*}{ P value } \\
\cline { 2 - 8 } & \multicolumn{2}{c}{ Pendek } & \multicolumn{2}{c}{ Sangat Pendek } & \multicolumn{2}{c}{ Total } & \\
\cline { 2 - 7 } & $\mathrm{f}$ & $\%$ & $\mathrm{f}$ & $\%$ & $\mathrm{f}$ & $\%$ & \\
\hline Baik & 29 & 49,2 & 14 & 23,7 & 43 & 72,9 & \\
\hline Kurang Baik & 12 & 20,3 & 4 & 6,8 & 16 & 27,1 & \multirow{2}{*}{0,021} \\
\hline Jumlah & 41 & 69,5 & 18 & 30,5 & 59 & 100 & \\
\hline
\end{tabular}

Berdasarkan hasil uji Chi Square diperoleh $\mathrm{P}_{\text {value }} 0,021<0,05$, sehingga $\mathrm{Ha}$ diterima dan $\mathrm{Ho}$ di tolak, yang berarti ada hubungan
Pola Asuh dengan Kejadian Stunting di Wilayah Puskesmas Kabupaten Pati.

Tabel.12

Tabulasi Silang Antara Berat Badan Lahir dengan Kejadian Stunting di Wilayah Puskemas Kabupaten Pati

\begin{tabular}{|c|c|c|c|c|c|c|c|}
\hline \multirow{3}{*}{ Berat Badan Lahir } & \multicolumn{4}{|c|}{ Kejadian Stunting } & & & \multirow{3}{*}{$P$ value } \\
\hline & \multicolumn{2}{|c|}{ Pendek } & \multicolumn{2}{|c|}{ Sangat Pendek } & \multicolumn{2}{|c|}{ Total } & \\
\hline & $f$ & $\%$ & $\mathrm{f}$ & $\%$ & $\mathrm{f}$ & $\%$ & \\
\hline$\geq 2500$ gram & 31 & 52,5 & 12 & 20,3 & 43 & 72,9 & \\
\hline$<2500$ gram & 10 & 16,9 & 6 & 10,2 & 16 & 27,1 & 0,020 \\
\hline Jumlah & 41 & 69,5 & 18 & 30,5 & 59 & 100 & \\
\hline
\end{tabular}

Berdasarkan hasil uji Chi Square diperoleh $\mathrm{P}_{\text {value }} 0,020<0,05$, sehingga $\mathrm{Ha}$ diterima dan Ho di tolak, yang berarti ada hubungan
Berat Badan Lahir dengan Kejadian Stunting di Wilayah Puskesmas Kabupaten Pati.

Tabel. 13

Tabulasi Silang Antara Ekonomi dengan Kejadian Stunting di Wilayah Puskemas Kabupaten Pati

\begin{tabular}{|c|c|c|c|c|c|c|c|}
\hline \multirow{3}{*}{ Ekonomi } & \multicolumn{4}{|c|}{ Kejadian Stunting } & & & \multirow{3}{*}{ Pvalue } \\
\hline & \multicolumn{2}{|c|}{ Pendek } & \multicolumn{2}{|c|}{ Sangat Pendek } & \multicolumn{2}{|c|}{ Total } & \\
\hline & $\mathrm{f}$ & $\%$ & $\mathrm{f}$ & $\%$ & $\mathrm{f}$ & $\%$ & \\
\hline$\geq \mathrm{UMR}$ & 19 & 32,2 & 9 & 15,3 & 28 & 47,5 & \\
\hline$<\mathrm{UMR}$ & 22 & 37,3 & 9 & 15,3 & 31 & 52,5 & 0,001 \\
\hline Jumlah & 41 & 69,5 & 18 & 30,5 & 59 & 100 & \\
\hline
\end{tabular}

Berdasarkan hasil uji Chi Square diperoleh $\mathrm{P}_{\text {value }} 0,001<0,05$, sehingga Ha diterima dan Ho di tolak, yang berarti ada hubungan
Ekonomi dengan Kejadian Stunting di Wilayah Puskesmas Kabupaten Pati. 
Analisa Multivariat Pengetahuan, Pemberian ASI Eksklusif, Riwayat Penyakit Infeksi, Pola Asuh, Berat Badan Lahir, Ekonomi Terhadap Kejadian Stunting pada Balita di Wilayah Puskesmas Kabupaten Pati

\begin{tabular}{c|c|c}
\hline Variabel & Koefisien Regresi & P value \\
\hline Pengetahuan & 1.120 & 0,170 \\
Pemberian ASI Eksklusif & 1.447 & 0,210 \\
Riwayat Penyakit Infeksi & 1.392 & 0,320 \\
Pola Asuh & 1.364 & 0,004 \\
Berat Badan Lahir & 1.527 & 0,007 \\
Ekonomi & 1.124 & 0,011 \\
\hline Constan & 3.852 & 0.000 \\
\hline
\end{tabular}

Hasil uji multivariate dilakukan melalui uji regresi logistis berganda yang bertujuan untuk mengetahui pengaruh variabel bebas secara bersama-sama terhadap variabel terikat. Adapun hasil uji multivariate terilihat pada tabel di atas ini. Berdasarkan analisis di atas menunjukkan bahwa

\section{PEMBAHASAN}

Faktor yang mempengaruhi kejadian stunting pada balita sesuai penelitian diatas didapatkan hasil bahwa pengetahuan yang dimiliki oleh responden sebagian besar dalam kategori cukup $(42,4 \%)$. Berdasarkan kuesioner yang diberikan menunjukkan bahwa responden cukup memahami bahwa makanan yang diberikan kepada balita sebaiknya makanan yang beranekaragam agar anak tidak merasa bosan dan malas makan, jika terlalu banyak memberi makanan ringan sebelum waktu makan, akan mengganggu nafsu makan anak, balita 1-5 tahun diberikan makanan utama sebanyak 3 kali sehari ditambah makanan selingan diantara setiap makanan utama, anak usia 1-5 tahun mempunyai rasa ingin tahu yang lebih tinggi untuk itu ibu sebaiknya memiliki keterampilan yang baik dalam mengolah makanan. Hal ini menunjukkan bahwa tingkat pengetahuan ibu mengenai gizi merupakan salah satu faktor yang dapat mempengaruhi terjadinya stunting pada anak balita. variabel yang berpengaruh terhadap kejadian stunting pada balita pola asuh (Pvalue $(0,004)$, berat badan lahir (Pvaluae 0,007) dan Ekonomi (Pvalue 0,011).

Hasil penelitian yang dilakukan oleh Ni'mah, K \& Nadhiroh, S.R. (2015) mengenai pengetahuan ibu tentang gizi pada balita menunjukkan bahwa keluarga pada kelompok balita normal cenderung berpenghasilan cukup (50\%) dibandingkan dengan keluarga balita stunting $(23,5 \%)$. Selain itu penelitian oleh Olsa Danie E \& dkk.(2017) menunjukkan hasil bahwa pengetahuan ibu sebagian besar berada pada tingkat pengetahuan yang cukup (48,7\%), tingkat pengetahuan yang baik sebesar $25,4 \%$ dan tingkat pengetahuan yang kurang sebesar 25,9\%. Salah satu penyebab gangguan gizi adalah kurangnya pengetahuan gizi dan kemampuan seseorang menerapkan informasi tentang gizi dalam kehidupan sehari-hari. Tingkat pengetahuan gizi ibu mempengaruhi sikap dan perilaku dalam memilih bahan makanan, yang lebih lanjut akan mempengaruhi keadaan gizi keluarganya (Suhardjo, 2013).

Penelitian juga menilai keterkaitan antara pengetahuan dengan kejadian stunting, diperoleh hasil bahwa 
nilai $\mathrm{P}_{\text {value }} 0,039<0,05$, sehingga $\mathrm{Ha}$ diterima dan Ho di tolak, yang berarti ada hubungan pengetahuan dengan kejadian stunting di Wilayah Puskesmas Kabupaten Pati. Penelitian ini sejalan dengan penelitian oleh Olsa, E.D \& dkk (2017) menunjukkan hasil bahwa nilai $\mathrm{p}=0,000(\mathrm{p}<0,05)$ yang artinya terdapat hubungan yang bermakna antara pengetahuan ibu dengan kejadian stunting pada anak baru masuk sekolah dasar di Kecamatan Nanggalo Kota Padang. Pengetahuan mengenai gizi merupakan proses awal dalam perubahan perilaku peningkatan status gizi, sehingga pengetahuan merupakan faktor internal yang mempengaruhi perubahan perilaku. Pengetahuan ibu tentang gizi akan menentukan perilaku ibu dalam menyediakan makanan untuk anaknya. Ibu dengan pengetahuan gizi yang baik dapat menyediakan makanan dengan jenis dan jumlah yang tepat untuk mendukung pertumbuhan dan perkembangan anak balita.

Hasil penelitian faktor ASI Esklusif menunjukkan sebagian besar responden memberikan ASI Eksklusif kepada balita sebanyak 33 orang $(55,9 \%)$. Hal ini dapat di ketahui dari hasil jawaban kuesioner bahwa alasan ibu balita memberikan ASI Eksklusif pada anaknya karena ASI sangat bermanfaat untuk system kekebalan tubuh, dengan menyusui dapat mempererat hubungan batin antara anak dan ibu, tidak perlu mengeluarkan biaya, dapat meningkatkan kecerdasan anak dan makanan pendamping diberikan pada anak setelah usia 6 bulan.

Penelitian yang dilakukan oleh Mugianti, Sri \& dkk (2018) menunjukkan hasil bahwa 67,7\% (21 anak) mendapatkan ASI Ekslusif dan 32,3\% (10 anak) tidak mendapatkan ASI Ekslusif hal ini didasari bahwa 48,4\% (15 ibu) memiliki pendidikan rendah, 45,2\% (14 ibu) memiliki pendidikan menengah dan 6,5\% (2 ibu) memiliki pendidikan tinggi.

Hasil uji statistic menunjukkan hasil bahwa nilai $\mathrm{P}_{\text {value }} 0,040<0,05$, sehingga Ha diterima dan Ho di tolak, yang berarti ada hubungan Pemberian ASi Eksklusif dengan Kejadian Stunting di Wilayah Puskesmas Kabupaten Pati. Hal ini sejalan dengan penelitian penelitian Wardah (2012), menyatakan bahwa pemberian ASI Eksklusif merupakan faktor resiko kejadinya stunting $(\mathrm{p}<0,05)$. Demikian pula dengan hasil penelitian Anggiana, et al (2013), pemberian ASI Eksklusif secara klinis berpengaruh terhadap pertumbuhan anak, dimana anak yang stunting banyak ditemukan pada mereka yang tidak memberikan ASI Eksklusif. Anak yang tidak diberikan ASI Eksklusif memiliki resiko 3,4 kali lebih besar untuk menjadi stunting dibandingkan dengan anak yang yang diberi ASI Eksklusif $(\mathrm{OR}=3,4)$.

ASI Ekslusif penting dalam pertumbuhan anak untuk mengurangi dan mencegah terjadinya penyakit infeksi pada anak, sehingga perilaku ibu dalam pemberian ASI ekslusif memiliki hubungan yang bermakna dengan indeks TB/U (Tinggi Badan menurut Umur), dimana 48 dari 51 anak stunting tidak mendapatkan ASI eksklusif.

Hasil penelitian pada faktor riwayat penyalit infeksi menunjukkan bahwa balita yang mempunyai riwayat infeksi sebanyak 14 orang $(23,7 \%)$ dan yang tidak memepunyai riwayat infeksi sebanyak 45 orang (76,3\%). Hasil penelitian yang dilakukan oleh Mugianti, Sri \& dkk (2018) menunjukkan bahwa terdapat $80,6 \%$ (25 anak) menderita penyakit infeksi dalam satu bulan terahir dan 19,4\% (6 anak) tidak sakit. Terdapat interaksi bolak balik antara status gizi dengan penyakit infeksi. Malnutrisi dapat meningkatkan risiko infeksi, sedangkan infeksi dapat menyebabkan 
malnutrisi, yang mengarahkan ke lingkaran setan. Anak kurang gizi, yang daya tahan terhadap penyakitnya rendah, jatuh sakit dan akan semakin kurang gizi, sehingga mengurangi kapasitasnya untuk melawan penyakit dan sebagainya.

Hasil uji statistic menunjukkan hasil bahwa $\mathrm{P}_{\text {value }} 0,014<0,05$, sehingga Ha diterima dan Ho di tolak, yang berarti ada hubungan Riwayat Penyakit Infeksi dengan Kejadian Stunting di Wilayah Puskesmas Kabupaten Pati. Hal ini sejalan dengan penelitian Aridiyah, dkk (2015) menunjukkan hasil bahwa riwayat penyakit infeksi dengan kejadian stunting pada anak balita yang berada di pedesaan maupun perkotaan memiliki hubungan yang signifikan yaitu dengan nilai pvalue berturut-turut yaitu 0,017 dan $0,001<\alpha(0,05)$.

Konsumsi makanan dan riwayat penyakit infeksi bersifat saling mendorong (berpengaruh). Anak balita yang tidak mendapat cukup makanan bergizi seimbang memiliki daya tahan yang rendah terhadap penyakit sehingga mudah terserang infeksi. Sebaliknya penyakit infeksi dapat mengakibatkan asupan gizi tidak dapat diserap tubuh dengan baik sehingga berakibat gizi buruk.

Hasil penelitian pada faktor pola asuh menunjukkan bahwa pola asuh yang diberikan dalam kategori baik sebanyak 43 orang $(72,9 \%)$ dan pola asuh kurang baik sebanyak 16 orang $(27,1 \%)$. Sedangkan hasil uji chi square meunjukkan nilai $\mathrm{P}_{\text {value }} 0,021<0,05$, sehingga Ha diterima dan Ho di tolak, yang berarti ada hubungan Pola Asuh dengan Kejadian Stunting di Wilayah Puskesmas Kabupaten Pati. Penelitian ini sejalan dengan Penelitian Debora (2011) yang menyatakan bahwa pola asuh memiliki hubungan yang signifikan $(\mathrm{p}<0,05)$ terhadap kejadian stunting. Begitu juga dengan penelitian Sarah, et al (2013) menyatakan bahwa pola asuh memiliki kontribusi yang besar dalam proses pertumbuhan anak dimana pola asuh menunjukkan hubungan yang signifikan dengan kejadian stunting pada anak usia 6-23 bulan di wilayah pesisir kecamatan Tallo kota Makasar.

Pola asuh kesehatan merupakan faktor penting dalam meningkatkan pertumbuhan balita yang optimal. Dimana pola asuh makan yang baik berdampak ada status gizi anak normal. Praktek pemberian makan pada anak sangat penting dan besar pengaruhnya bagi pertumbuhan anak. Memberikan suasana yang nyaman bagi anak pada saat makan, mengetahui selera makan yang baik pada anak, sabar dan penuh perhatian pada saat memberikan makan tentu dapat menjalin keakraban di antara keduanya sehingga diharapkan anak mampu menghabiskan makanan yang diberikan.

Hasil peenlitian pada faktor berat badan lahir menunjukkan bahwa berat badan lahir bayi $\geq 2500$ gram sebanyak 43 balita $(72,9 \%)$ dan berat badan lahir < 2500 gram sebanyak 16 balita $(27,1 \%)$. Berat lahir memberikan kontribusi utama pada tahun pertama lalu menyusul proses menyusui, pelayanan kesehatan dan postur ibu yang tinggi secara signifikan menurunkan kemungkinan terhambatnya pertumbuhan anak. Berdasarkan hasil uji chi square menunjukkan hasil bahwa nilai $\mathrm{P}_{\text {value }}$ $0,020<0,05$, sehingga Ha diterima dan Ho di tolak, yang berarti ada hubungan Berat Badan Lahir dengan Kejadian Stunting di Wilayah Puskesmas Kabupaten Pati.

Peneltian ini sejalan dengan penelitian Taguri, et al (2009) dan Fitri (2012) menyatakan bahwa berat badan lahir rendah berhubungan secara signifikan dengan stunting pada balita $(\mathrm{p}<0,05)$. Balita yang mempunyai berat badan lahir rendah beresiko menjadi 
stunting 1,7 kali dibanding balita yang mempunyai berat badan lahir normal.

Karakteristik bayi saat lahir (BBLR atau BBL normal) merupakan hal yang menentukan pertumbuhan anak. Anak dengan riwayat BBLR mengalami pertumbuhan linear yang lebih lambat dibandingkan anak dengan riwayat BBL normal. Disamping itu ibu dengan gizi kurang sejak awal sampai akhir kehamilan dan menderita sakit akan melahirkan BBLR, yang kedepannya menjadi anak stunting, selain itu bayi yang diiringi dengan konsumsi makanan yang tidak adekuat, dan sering terjadi infeksi selama masa pertumbuhan menyebabkan terhambatnya pertumbuhan.

Hasil penlitian pada faktor ekonomi menunjukkan hasil bahwa ekonomi responden $\geq$ UMR sebanyak 31 orang $(52,5 \%)$ dan tingkat ekonomi < UMR sebanyak 28 orang $(46,5 \%)$. Penelitian yang dilakukan oleh Ngaisyah, Dewi (2015) menunjukkan hasil bahwa pada kelompok stunting lebih banyak pendapatannya adalah dibawah UMR yakni sebanyak 67 responden $(35,8 \%)$, sedangkan yang memiliki pendapatan diatas UMR hanya sedikit yakni sebanyak 45 orang (22\%). Hal ini sesuai dengan pendapat Sulistyoningsih bahwa meningkatnya pendapatan akan meningkatkan peluang untuk membeli pangan dengan kualitas dan kuantitas yang lebih baik, sebaliknya penurunan pendapatan akan menyebabkan menurunnya daya beli pangan yang baik secara kualitas maupun kuantitas.

Hasil analisis uji chi square menunjukkan hasil bahwa nilai $\mathrm{P}_{\text {value }}$ $0,001<0,05$, sehingga Ha diterima dan Ho di tolak, yang berarti ada hubungan Ekonomi dengan Kejadian Stunting di Wilayah Puskesmas Kabupaten Pati. Penelitian ini sejalan dengan penelitian marfina (2014) diperoleh nilai $p<0,05$, artinya ada hubungan status ekonomi dengan terjadinya stunting. Ekonomi keluarga merupakan penyebab tidak langsung terhadap status gizi anak karena berkaitan kepada pendapatan keluarga sebagai faktor yang menentukan terhadap kuantitas dan kualitas makanan yang dikonsumsi didalam keluarga dan rendahnya pendapatan juga dapat menyebabkan daya beli terhadap makanan menjadi rendah dan konsumsi pangan keluarga akan berkurang. Kondisi ini akhirnya akan mempengaruhi kesehatan dan status gizi keluarga.

Sedangkan hasil uji analisis multivariat menunjukkan hasil bahwa variabel yang secara bersama-sama berpengaruh terhadap kejadian stunting yaitu faktor pola asuh $(\mathrm{p}=0,004)$, berat badan lahir $(\mathrm{p}=0,007)$ dan ekonomi $(\mathrm{p}=0,011)$. Hal ini dijelaskan bahwa praktek pengasuhan yang memadai sangat penting tidak hanya bagi daya tahan anak tetapi juga mengoptimalkan perkembangan fisik dan mental anak serta baiknya kondisi kesehatan anak. Pengasuhan juga memberikan kontribusi bagi kesejahteraan dan kebahagian serta kualitas hidup yang baik bagi anak secara keseluruhan. Sebaliknya jika pengasuhan anak kurang memadai, terutama keterjaminan makanan dan kesehatan anak bisa menjadi salah satu faktor yang menghantarkan anak menderita kurang gizi.

Berat badan lahir berpengaruh terhadap pertumbuhan dan perkembangan anak dimasa yang akan datang. Berat badan lahir rendah erat kaitannya dengan kurang gizi selama kehamilan. Selain berdampak pada angka kematian bayi, berat badan lahir rendah juga berdampak pada tingginya kasus gizi kurang dan gizi buruk pada anak balita.

Pendapatan keluarga yang baik dapat menunjang tumbuh kembang anak 
karena orang tua dapat menyediakan semua kebutuhan anaknya. Adanya ketidakmampuan kepala keluarga dalam memenuhi kebutuhan gizi anaknya baik dari segi kualitas maupun kuantitasnya sehingga berdampak pada petumbuhan gizi anak. Masih rendahnya tingkat pendapatan keluarga merupakan rintangan yang menyebabkan keluarga tidak mampu memenuhi kebutuhan baik pangan maupun non pangan dalam jumlah yang dibutuhkan.

\section{KESIMPULAN DAN SARAN}

Hasil penelitian menunjukkan bahwa ada hubungan antara faktor pengetahuan, pemebrian ASI Eksklusif, Riwyat penyakit infeksi, pola asuh, berat badan lahir dan ekomoni terhadap kejadian stunting di Wilayah Puskesmas Kabupaten Pati dengan Pvalue> 0,005. Sedangkan faktor yang sangat berpengaruh terhadap kejaidan stunting adalah faktor pola asuh $(\mathrm{p}=0,004)$, berat badan lahir $(\mathrm{p}=0,007)$ dan ekonomi $(\mathrm{p}=0,011)$. Sangat penting bagi masyarakat terutama ibu dan keluarga yang memiliki anak dibawah 5 tahun agar mematuhi dan melaksanakan program terkait dengan pemberian gizi seimbang pada balita dan menambah kreatifitas untuk pemberian makanan pada anaknya.

\section{DAFTAR PUSTAKA}

1. Kemenkes RI, 2018. Situasi Balita Pendek (Stunting) di Indonesia. Pusat Data dan Informasi. Jakarta

2. Riskesdas. 2018. Hasil Utama Riskesdas. Kementerian Kesehatan Badan Penelitian dan Pengembangan Kesehatan. Jakarta

3. BAPPENAS, 2011 Rencana Aksi Nasional Pangan dan Gizi 20112015, Jakarta

4. Hutasoit, H,M,A,I. 2012. Analisis Faktor Risiko Stunting Pada Anak

$\begin{aligned} & \text { Sekolah Dasar Di } \begin{array}{r}\text { Kabupaten } \\ \text { Utara. }\end{array} \\ & \text { Tapanuli } \\ & \text { http://repository.usu.ac.id/handle/1 }\end{aligned}$
$\underline{\text { 23456789/59020 }}$

5. Marfina. 2013. Faktor-Faktor Yang Memengaruhi Kejadian Stunting Pada Anak Usia 12-24 Bulan di Kecamatan Ulee Kareng Kota Banda Aceh. http://repository.usu.ac.id/handle/1 23456789/61604?show=full

6. Hayati AW, Hardinsyah, Jalal F, Madanijah S, Briawan D. 2012. Determinan Stunting Anak Baduta. WNPG X Nov 20-21. Jakarta: LIPI

7. Anugraheni, HS dan Kartasurya, MI. 2012. Faktor Risiko Kejadian Stunting pada Anak Usia 12-36 Bulan di Kecamatan Pati, Kabupaten Pati. Journal of Nutrition College. Volume 1, Nomor 1 (30-37).

8. AL - Rahmad Ah, Miko A, Hadi A. 2013. Kajian Stunting Pada Anak Balita Ditinjau Dari Pemberian ASI Eksklusif, MP-ASI, Status Imunisasi, Dan Karakteristik Keluarga Di Kota Banda Aceh. Jurnal Kesehatan Ilmiah Nasawakes. 6(2) : $169-184$

9. Agustina, A. 2015. Faktor-faktor Risiko Kejadian Stunted pada Balita (24-59 bulan) di Wilayah Kerja Puskesmas Sosial Palembang Tahun 2014.

https://ejournal3.undip.ac.id/index.p hp/jkm/article/download/19900/188 $\underline{12}$

10. Notoatmodjo, Soekidjo. 2012. Promosi Kesehatan dan Perilaku Kesehatan. Jakarta: Rineka Cipta.

11. Setiawan, Eko. Dkk. 2018. FaktorFaktor yang Berhubungan dengan Kejadian Stunting pada Anak Usia 24-59 Bulan di Wilayah Kerja Puskesmas Andalas Kecamatan Padang Timur Kota Padang. 
http://jurnal.fk.unand.ac.id/index.ph $\mathrm{p} / \mathrm{jka} / \mathrm{article} / \mathrm{download} / 813 / 669$

12. Anugraheni, H. S. 2012. Faktor Risiko Kejadian Stunting pada anak usia 12-36 bulan di kecamatan Pati, Kabupaten Pati (Skripsi, Universitas Diponegoro, Semarang). Diakses dari http://www.ejournals1.undip.ac.id

13. Meilyasari, F. \& Isnawati, M. 2014. Faktor risiko kejadian stunting pada balita usia 12 bulan di Desa Purwokerto Kecamatan Patebon, Kabupaten Kendal. Journal of Nutrition College, 3(2), 16-25. Diakses dari http://www,ejournals1.undip.ac.id

14. Ni'mah, K \& Nadhoroh, S.R. 2015. Faktor Yang Berhubungan dengan Kejadian Stunting Pada Balita. https://e-

journal.unair.ac.id/mgi/article/downl $\mathrm{oad} / 3117 / 2264$

15. Aridiyah Okky F, dkk. 2015. Faktorfaktor yang Mempengaruhi Kejadian Stunting pada Anak Balita di Wilayah Pedesaan dan Perkotaan. https://jurnal.unej.ac.id/index.php/JP $\underline{\text { K/article/download/2520/2029 }}$
16. 17 Hubungan Sikap dan Pengetahuan Ibu Terhadap Kejadian Stunting Pada Anak Baru Masuk Sekolah Dasar di Kecamatan Naggalo.

http://jurnal.fk.unand.ac.id/index.ph $\mathrm{p} / \mathrm{jka} / \mathrm{article} / \mathrm{download} / 733 / 589$

17. Mugianti, Sri \& dkk. 2018. Faktor penyebab anak Stunting usia 25-60 bulan di Kecamatan Sukorejo Kota Blitar.

https://jnk.phb.ac.id/index.php/jnk/a rticle/view/374

18. Yudianti, Rahmat Haji Saeni. 2016. Pola Asuh Dengan Kejadian Stunting Pada Balita Di Kabupaten Polewali Mandar. https://jurnal.poltekkesmamuju.ac.id /index.php/m/article/download/9/8

19. Ngaisyah, Dewi. 2015. Hubungan Sosial Ekonomi Dengan Kejadian Stunting Pada Balita Di Desa Kanigoro, Saptosari, Gunung Kidul Http://Medika.Respati.Ac.Id/Index. $\underline{\mathrm{Php} / \text { Medika/Article/Viewfile/105/1 }}$ $\underline{01}$ 